Medicine in the elderly

\title{
Assessment and treatment of nutritional status in stroke patients
}

\author{
S E Gariballa, A J Sinclair
}

\section{Summary}

Stroke illness imposes a heavy and costly work load on hospital and community care services, and life after stroke can be a miserable affair for stroke patients and their carers. Nutritional factors may have an important role in acute stroke and its outcome. From the limited amount of research undertaken it has been shown that a significant number of patients with stroke are undernourished on admission and their nutritional status deteriorates further as an in-patient. This is especially so for those who are most dependent, in whom undernutrition is also associated with increasing morbidity and mortality. There is some evidence that nutritional supplementation may improve nutritional status and reduce morbidity and mortality. However most clinically available nutrition screening instruments lack sensitivity and specificity, and abnormal nutritional indicators may simply reflect effects of age, functional disability, or severe underlying disease. Therefore, causal relationship cannot be assumed without a sufficiently powerful intervention study which adequately adjusts for the effects of non-nutritional factors, such as the number and severity of comorbid conditions on clinical outcome. Meanwhile, doctors, nurses and members of the multidisciplinary team looking after stroke patients should be made aware of the likely impact of poor nutritional status on clinical outcome.

Keywords: stroke; nutritional status; elderly

\author{
Academic Department of Geriatric \\ Medicine, University of Birmingham, \\ Selly Oak Hospital, The Hayward \\ Building, Raddlebarn Road, \\ Birmingham B29 6JD, UK \\ S E Gariballa \\ A J Sinclair \\ Accepted 21 January 1998
}

Ill-health frequently has an adverse effect on nutritional status, especially in elderly people. For many, these effects are limited to the time of acute illness and the temporary nutritional disadvantage is overcome, depending on the body reserve, once their customary pattern of eating is resumed. Repeated episodes of ill-health or prolonged illness may lead to a decline in nutritional status in a stepwise manner. ${ }^{1}$ There is evidence that good nutrition contributes to the healthy well-being of elderly people and to their ability to recover from illness. ${ }^{1}$ Stroke is more common in the sixth, seventh and eighth decades of life. There are problems in diagnosing protein-energy undernutrition (PEU) in the elderly because of physical and biochemical changes which may take place as part of normal ageing processes, and most clinically available nutrition screening instruments individually lack sensitivity and specificity. ${ }^{2}$ Stroke patients may be more at risk than other groups because of physical and mental incapacity, problems with perception and communication, swallowing difficulties and prolonged hospital stay. The fast phase of recovery for stroke patients may take a few weeks, and slow down thereafter but probably continues for at least 6 months for not less than a third of survivors. ${ }^{3}$ Overall metabolic requirements in the acute or long-term post-stroke period are not well described. The aims of this article are to review existing evidence in relation to assessment and treatment of nutritional status in stroke patients and to identify areas which need further research.

\section{Assessment of nutritional status in elderly people}

PEU is a state of starvation resulting in a reduction in body cell mass. Identification of PEU has been based on objective measurements, including anthropometric, haematological, biochemical, immunological and clinical assessment scores. No single measurement is sufficiently sensitive and specific in identifying PEU. ${ }^{4}$ At present, nutritional assessment has three main goals. The first is to define the type and severity of PEU; the second is the identification of high-risk patients; and the third is to monitor the efficacy of nutritional support. Table 1 shows some of these measures, their role in identifying patients at risk of PEU and their limitations in relation to elderly people.

\section{Neurological deficit following acute stroke}

Not all strokes produce the complete range of neurological deficits and there is an almost infinite range of possible combinations of loss of function. The more common deficits include: disturbed level of consciousness (30-40\%), difficulty in swallowing (30\%), motor weakness (50-80\%), disturbance of sensory function $(25 \%)$, slurred speech $(30 \%)$, dysphasia / aphasia $(30 \%)$, and visual field defects $(7 \%) .^{5}$ About $30 \%$ of patients present with alteration in or loss of consciousness as their major clinical feature, and a further $10 \%$ will be drowsy in addition to their other symptoms. These deficits will have a variable impact on the nutritional demands and actual intake of patients with stroke.

For example, hemiplegia can affect nutritional intake in several ways. If a patient's dominant side is affected, the patient will have to use the nondominant hand which will make eating difficult and tedious. Motor movement and sensory input necessary for chewing and swallowing can be affected as well. During mastication, decreased sensation can cause pouching of food on the affected side without the patient being aware of it. Perceptual and visual field defects, cognitive impairment as well as motor apraxia can lead to decrease food intake and hence affect nutritional status. Dysphagia or difficulty in swallowing has obvious implications for nutritional intake. Gordon et at have demonstrated that dysphagia complicates $43 \%$ of first episode hemispheric stroke; $86 \%$ of those affected were able to swallow normally two weeks later. Immobility is another important factor which affects nutritional status of stroke patients in several 
Table 1 Nutritional assessment: aims and limitations

\begin{tabular}{|c|c|c|}
\hline Aims & Measures used to assess nutritional status & Limitations \\
\hline \multirow[t]{4}{*}{ Defining type and severity of PEU } & $\begin{array}{l}\text { Clinical assessment (history and physical examination). } \\
\text { The simplest way is to ask about unintentional weight } \\
\text { loss }\end{array}$ & $\begin{array}{l}\text { May be as effective as other objective measurements. } \\
\text { Needs to be studied more scientifically. }\end{array}$ \\
\hline & $\begin{array}{l}\text { Anthropometric: weight, weight:height ratio, triceps } \\
\text { skinfold thickness, arm muscle area and arm fat area }\end{array}$ & $\begin{array}{l}\text { Lack of definition of normality or referral data. May } \\
\text { vary between and within population. Changes due } \\
\text { to ageing may affect some of these measurements. }\end{array}$ \\
\hline & $\begin{array}{l}\text { Biochemical: Serum albumin concentration is the most } \\
\text { widely used. To a lesser extent transferrin, prealbumin, } \\
\text { retinol binding protein and ceruloplasmin. }\end{array}$ & $\begin{array}{l}\text { No single biochemical indicator has proved the most } \\
\text { reliable. Variation may be due to causes other than } \\
\text { PEU such as abnormal distribution in the } \\
\text { extravascular space, or increased catabolism, or net } \\
\text { loss, disease process, or a combination. }\end{array}$ \\
\hline & Immunological: Lymphocytopenia and anergy to skin tests & $\begin{array}{l}\text { The similarity of the effects of ageing and PEU on } \\
\text { immune function places the usefulness of routine } \\
\text { immunological testing in this population in question }\end{array}$ \\
\hline Identification of high risk patients & $\begin{array}{l}\text { Different combinations of several different markers have } \\
\text { been proposed by different workers such as: Buzby } e t \text { al, } \\
\text { identified four related factors (serum albumin, serum } \\
\text { transferrin, triceps skinfold thickness and delayed } \\
\text { hypersensitivity). Klidjian } e t \text { al, }{ }^{26} \text { has shown that reduced } \\
\text { arm muscle circumference and impaired skeletal } \\
\text { function measured by forearm muscle dynamometry has } \\
\text { been positively correlated with an increased risk of } \\
\text { postoperative complications }\end{array}$ & $\begin{array}{l}\text { Standardised nutritional variables are not yet } \\
\text { available in clinical practice. The factors } \\
\text { determining the risk of PEU are multiple and } \\
\text { interrelated, and include the patient's previous } \\
\text { nutritional status, the disease process itself and the } \\
\text { magnitude and anticipated duration of associated } \\
\text { catabolic stresses. }\end{array}$ \\
\hline Monitoring the efficacy of nutritional support & $\begin{array}{l}\text { Selected biochemical variables such as serum albumin } \\
\text { concentration, prealbumin concentration, transferrin } \\
\text { value, retinol binding protein value and fibronectin } \\
\text { are used to determine if a patient is responding to the } \\
\text { nutritional support programme. Maintenance of a } \\
\text { positive nitrogen balance and weight gain may be useful } \\
\text { as well. }\end{array}$ & $\begin{array}{l}\text { Monitoring should be more intensive in the early } \\
\text { phases and major functions (renal, hepatic, } \\
\text { cardiovascular) should be evaluated. Monitoring } \\
\text { the efficacy of nutritional support is the most } \\
\text { difficult and controversial. Different centres use } \\
\text { different approaches. }\end{array}$ \\
\hline
\end{tabular}

^Fibronectin is an opsonic glycoprotein. During starvation values fall by $25-30 \%$. Has been proposed as a sensitive index of nutritional depletion and repletion.

\begin{tabular}{|l|}
\hline Nutritional assessment \\
\hline abnormal nutritional indicators may \\
reflect effects of age, functional \\
disability, or underlying disease \\
available nutrition screening \\
instruments lack sensitivity and \\
specificity; however, in combination, \\
they provide accepted measurements \\
of nutritional status \\
of particular importance are \\
involuntary body weight changes, arm \\
muscle circumference, skinfold \\
measurement, and depressed levels of \\
secretory proteins
\end{tabular}

Box 1 ways: increased protein needs due to muscle wasting, loss of calcium from bones, and decubitus ulcers due to skin necrosis caused by excessive and prolonged pressure, which leads to excess nitrogen loss. Negative nitrogen balance induced by the immobility in turn increases patient's susceptibility to further skin ulceration. $^{7}$

Assessment, recognition and treatment of PEU remains an important problem in hospitals. The reason for this may be that nutritional assessment is not recognised as an integral part of a patient's clinical management. Therefore, one of the causes of the decreased nutritional intake of stroke patients, may be that the staff looking after them may not be specifically trained to assess and meet their nutritional demands.

\section{Eating problems following stroke}

Florence Nightingale wrote in her Notes on nursing, published in 1859: "Remember that sick cookery should half do the work of your patient's weak digestion. But if you further impair it with your bad articles, I know not what is to become of him or it. If the nurse is an intelligent being, and not a mere carrier of diets to and from the patient, let her exercise her intelligence in these things."

Although there are few who would argue against the importance of nutrition as part of the short and long term management of stroke patients, the dietician is not often regarded as an integral component of the multidisciplinary team. Some studies have demonstrated that eating problems such as anorexia, dysphagia, and chewing difficulties are common in stroke patients, and that the proportion of undernourished patients is higher on discharge than on admission. ${ }^{8}$ Stroke sequelae were found to be the second most common reason for permanent spoon feeding in nursing homes in the Umea region, Sweden. ${ }^{9}$ Axelsson $e t$ al ${ }^{\beta}$ studied eating problems and nutritional status of 32 consecutive stroke patients who stayed in hospital for more than 21 days. Eating problems were identified by direct observation of patients eating behaviour, interviews on admission, inspection of the mouth, and discussion with patients. Nutritional status was assessed by weight, triceps skinfold thickness, arm muscle circumference, plasma albumin, serum transferrin and plasma pre-albumin, on admission and then weekly. Eating problems were identified in 27 patients and poor nutritional status was found to be associated with (in decreasing order) low self-care performance, poor nutritional status on admission, male sex, intravenous energy-containing fluids, advanced age, paresis of the right arm and eating problems. ${ }^{8}$ In another study, Axelsson and her colleagues studied the eating 


\section{PEU following acute stroke}

- PEU is common, largely unrecognised in hospital patients on admission, and tends to get worse during the hospital stay

- although stroke patients are particularly at risk of PEU, the extent of this problem and it's contribution to stroke outcome is not presently known

- of particular importance is the influence of poor nutritional intake prior to PEG feeding on short- and long-term outcome in stroke patients with dysphagia

Box 2 behaviour of 104 stroke patients admitted to the stroke unit and found that 52 had eating problems which strongly correlated with length of stay or death. ${ }^{9}$

\section{PEU following acute stroke}

Among patients with acute stroke, PEU, measured by three anthropometric variables and by the levels of three circulating proteins, was reported at a frequency of $16 \%$ on admission. At discharge, $22 \%$ or more had two or more subnormal indicators, and PEU in hospital was related to infections, male sex, intake of cardiovascular drugs and age. ${ }^{10}$ Unosson et al ${ }^{11}$ studied the nutritional status of 50 consecutive stroke admissions aged 70 years or older. Anthropometric measurements, serum proteins, delayed hypersensitivity and body composition measured by bioelectric impedance were determined on admission, and 2 and 9 weeks later. Their findings showed that low serum albumin and anergy were common among stroke patients, more so among those who were heavily dependent. During the recovery period, patients used body fat to compensate for energy needs, and immobility led to loss of body cell mass.

A recent study of nutritional status of 104 patients with acute stroke at admission and after 1 week reported that PEU was associated with increased stress reaction during the first week and that it was an important predictor of poor prognosis. ${ }^{12}$ Our own work has shown that a significant number of acute stroke patients were undernourished after admission and during the hospital stay and undernutrition was associated with increasing morbidity and mortality. ${ }^{13} 14$

\section{Nutrition status and demands during stroke rehabilitation}

Nutritional depletion during rehabilitation may be more serious than during acute illness, since rehabilitation periods may extend over weeks and months, and weight loss, although less marked than in the early catabolic phase, may be greater overall. As long ago as 1971, Evans et al illustrated the relative neglect of the nutritional problems of rehabilitation patients. When they compared nutrient intakes of long-stay, acutely ill and rehabilitation patients, they showed energy and protein intakes to be the lowest in the latter group. ${ }^{15}$ Sullivan and Walls studied the nutritional status and energy intake of 350 randomly selected admissions, including stroke patients, to a geriatric rehabilitation unit. They found that PEU was a strong predictor of in-hospital mortality. After one year of follow-up of the same group of patients they reported that PEU was a strong independent risk factor for 1-year post-discharge mortality. ${ }^{16}{ }^{17}$ Furthermore, serum albumin as a clinical marker of PEU has been found to predict outcome in stroke and non-stroke patient rehabilitation units. ${ }^{16-18}$

\section{Nutritional support following stroke}

Nutritional support has been found to produce clinical benefit following acute illness in some settings. ${ }^{19-21}$ We have recently shown that oral nutritional supplementation significantly improved nutritional intake, prevented decline in nutritional status, and had a favourable but non-significant impact on clinical outcome after acute stroke. ${ }^{22}$ Young $e t a l^{33}$ demonstrated that early nutritional intervention improved neurological recovery in a group of patients with head injury. This study demonstrated that nutritional support has a positive role to play in the care and rehabilitation of patients with acute and chronic neurological problems. A retrospective study has shown that stroke patients fed within 72 hours of admission to a neurosurgical unit had a significantly shorter length of stay compared to those who received feeding later than 72 hours. $^{24}$

Many studies have shown that PEU is common in hospitalised patients and when present was found to be associated with increased morbidity and mortality. ${ }^{12}{ }^{16}$ On the other hand, nutritional support in undernourished patients has been shown to have beneficial effects on complication rates and clinical outcome in a variety of acute care settings. ${ }^{19-21}$ Table 2 shows established indications for the use of nutritional support in unselected groups of patients. ${ }^{4}$

\section{Nutritional status of dysphagic stroke patients}

Definitive diagnosis and further management of dysphagia after acute stroke should always involve speech and language therapists. However, early screening could easily and safely be carried out by the admitting nurse and/or doctor on those patients who are conscious and not known to have choked on fluids before. The patient should be helped to sit upright and then asked to drink $50 \mathrm{ml}$ of 
Table 2 Established indications for the use of nutritional support ${ }^{4}$

\begin{tabular}{|c|c|}
\hline Established indication & Benefit \\
\hline $\begin{array}{l}\text { Patients unable to eat or absorb nutrients for an indefinite period (permanent } \\
\text { neurological impairment, oropharyngeal dysfunction or short-gut syndrome) }\end{array}$ & Preserves nutritional status; lifesaving \\
\hline $\begin{array}{l}\text { Well-nourished, minimally stressed patients unable to eat for more than } 10-14 \\
\text { days }\end{array}$ & Preserves nutritional status; prevents starvation-induced complications \\
\hline $\begin{array}{l}\text { Severely malnourished patients who undergo major elective surgical procedures } \\
\text { Patients with major trauma (major blunt or penetrating trauma, head injury or } \\
\text { burn injury) }\end{array}$ & $\begin{array}{l}\text { Pre-operative nutrition decreases the incidence of major septic complications } \\
\text { Enteral nutrition is superior to parenteral nutrition in decreasing the incidence } \\
\text { of septic complications; nutritional support improves outcome in patients with } \\
\text { head injury }\end{array}$ \\
\hline Bone marrow transplant recipients undergoing intensive anticancer therapy & Improves outcome \\
\hline
\end{tabular}

Bone marrow transplant recipients undergoing intensive anticancer therapy head injury Improves outcome

water steadily from a medicine container. Gag reflex probably has no role in assessing ability to swallow.

Davalos et al recently studied the nutritional status of 104 stroke patients and reported that early enteral calorie feeding of those who had difficulty in swallowing did not prevent PEU during the first week and that PEU was an important predictor of poor outcome. ${ }^{12}$ Allison and colleagues described three stroke patients with prolonged swallowing difficulty whose rehabilitation had been hampered by repeated aspiration pneumonia and/or nasogastric tube dislodgement. Percutaneous gastrostomy tube feeding, initiated 4-6 months following the onset of stroke, was associated with nutritional improvement, marked functional recovery and eventual discharge from hospital. ${ }^{27}$ Recently a randomised prospective study of 30 in-patients with persistent dysphagia 14 days following acute stroke, compared percutaneous gastrostomy and nasogastric tube feeding. Patients fed via the gastrostomy tube had significantly lower mortality and a greater improvement in nutritional status at 6 weeks. ${ }^{28}$

\section{PEG feeding in dysphagic stroke patients: clinical and ethical issues}

Persistent dysphagia after acute stroke carries a poor prognosis; percutaneous endoscopic gastrotomy (PEG) insertion may be associated with increased complications and the majority of survivors need institutional care. ${ }^{629}$ The timing of PEG insertion, when indicated after acute stroke, is often many weeks after the stroke, during which period the nutritional intake of patients with persistent dysphagia is often very low. At present it is not known how much this low intake contributes to the poor outcome which often follows the PEG insertion, and whether improving the nutritional status prior to PEG feeding would influence the outcome. This important area is in need of urgent research, as it is not only likely to improve the management of dysphagic stroke patients only, but may also help in overcoming the ethical dilemma which surrounds PEG feeding in often heavily dependent stroke patients. It may also strengthen the case for early PEG feeding, even in those dysphagic stroke patients whose swallowing is likely to recover within few weeks.

\section{Assessment and treatment of nutritional status following stroke}

- dietetic advice must be regarded as an integral part of stroke patients management in hospital. It should be sought early to assess the most appropriate method of meeting individual nutritional requirements of stroke patients at risk

- assistance should be provided to stroke patients to make the right food choices and for those who find it difficult to feed themselves

- priorities should be given to meal times; nursing supervision should be available and stroke patients should be allowed enough time to eat

- health professionals should have access to the necessary basic training which will enable them to assess and meet the nutritional demands of stroke patients

\section{Conclusion and future directions}

Stroke patients are extremely vulnerable and many are likely to suffer from PEU during their hospital stay. The influence of nutrition and dietary factors on the incidence, clinical course and outcome of stroke is poorly understood and there is an important need for further research in certain areas such as:

- the value of clinical assessment (history and physical examination) as an effective measurement of nutritional status against objective measurements needs to be studied more scientifically

- biochemical markers such as serum albumin have long been used as a measure of health and disease. Many conditions, such as PEU, catabolic conditions, liver disease and renal disease, may reduce serum albumin levels. However, following acute illness such as stroke, further research is needed to reveal the true magnitude of the influence of PEU on secretory proteins such as serum albumin and to distinguish the influence of PEU from that of the catabolic state and other extraneous causes

- energy requirements and expenditure after acute stroke, and particularly during rehabilitation, is of particular interest; techniques to measure energy requirements and expenditure in these patients need to be validated

- the relationship between PEU and a poor outcome after acute illness should be established in well-designed nutritional intervention studies which adequately adjust for the effect of systematic and random bias. 
1 Department of Health and Social Security. Nutrition in the elderly. London: HMSO, 1992 Report on health and social subjects 43).

2 Mitchell CO, Lipschitz DA. Detection of protein-calorie malnutrition in the elderly. $A m \mathcal{F}$ Clin Nutr 1982;35:398-406.

3 Wade DT. Stroke: rehabilitation. Lancet 1992; 339:791-3.

4 Souba WW. Nutritional support. $N$ Engl $\mathcal{F}$ Med 1997;336:41-7.

5 Wade DT, Hewer RL, Skilbeck CE, et al. Stroke: A critical approach. London: Chapman and Hall, 1985 .

6 Gordon C, Langton Hewer R, Wade DT Dysphagia in acute stroke. $B M \mathcal{F}$ 1987;295:4114 .

74.

Mahony EH. Nutritional care of the stroke patient. Arch Phys Med Rehab 1973;54:569-70.

8 Axelsson K, Asplund K, Norberg A, et al. Eating problems of patients with severe stroke. $\mathcal{F} \mathrm{Am}$ Diet Assoc 1989;89:1092-6.

9 Axelsson K, Norberg A, Asplund K. Eating after stroke. Int Nurs Stud 1984;21:93-9.

10 Axelsson K, Asplund K, Norberg A, et al. Nutritional status in patients with acute stroke. Acto Med Scand 1988;224:217-24.

11 Unosson M, Ek AC, Bjurulf P, et al. Feeding dependence and nutritional status after acute stroke. Stroke 1994;25:366-71.

12 Davalos A, Ricart W, Gonzalez-Huix F, et al. Effect of malnutrition after acute stroke on Effect of malnutrition after acute stroke
13 Gariballa SE, Parker SG, Sinclair AJ, Castleden $\mathrm{CM}$. Serum albumin predicting functional outcome following acute stroke. Proceedings of the British Congress of Gerontology, July 1996; Manchester: Newton Mann Ltd.

14 Gariballa SE, Parker SG, Castleden CM. Serum albumin following acute stroke. Age Ageing 1996;26 (suppl 1):27.

15 Evans E, Stock AL. Dietary intake of geriatric patients in hospital. Nutr Metab 1971;13:21-35.

16 Sullivan DH, Walls RC. Impact of nutritional status on morbidity in a population of geriatric rehabilitation patients. F Am Geriatr Soc 1994; 42:471-7.

17 Sullivan DH, Walls RC, Bopp MM. Proteinenergy under nutrition and the risk of mortality. f Am Geriatr Soc1 995;43:507-12.

18 Aptaker RL, Roth EJ, Reichhardt G, et al. Serum albumin level as a predictor of geriatric
stroke rehabilitation outcome. Arch Phys Med stroke rehabilitation
Rehabil 1994;75:80-4

19 Bastow MD, Rawlings J, Allison SP. Benefits of supplementary tube feeding after fractured neck of femur. BMF 1983;287:1589-92.

20 Delmi M, Rapin C-H, Bengoa JM, et al. Dietary supplementation in elderly patients with fractured neck of femur. Lancet 1990:335:1013-6.

11 Larson J, Unosson M, Ek AC, et al. Ef dietary supplement on nutritional status and dietary supplement on nutritional status and clinical outcome in 501 geriatric patients. Clin
Nutr 1990;9:179-84.
22 Gariballa SE, Parker SG, Castleden CM. A randomised controlled trial of oral nutritional supplements following acute stroke. Age Ageing 1998; (suppl) in press.

23 Young B, Ott L, Twyman D, et al. The effect of nutritional support on outcome from severe head injury. $\mathcal{F}$ Neurosurg 1987;67:668-76.

24 Nyswonger GD, Helmchen RH. Early enteral nutrition and length of stay in stroke patients. $\mathcal{F}$ Neurosci Nurs 1992;24:220-3.

25 Buzby GP, Mullen JL, Mathews DC, Hobbs CL, Rosato EF. Prognostic nutritional index in gastrointestinal surgery. $A m \ngtr$ Surg 1979;139: gastrointe

26 Klidjian AM, Archer TJ, Foster KJ. Detection of dangerous malnutrition. $\mathcal{f}$ Parenteral Enteral Nutrit 1982;6:119-23.

27 Allison MC, Morris AJ, Park RHR, et al. Percutaneous endoscopic gastrotomy tube feeding may improve late outcome following stroke. $₹ R$ may improve late outcome
Soc Med 1992;85:147-9.

28 Norton B, Homer-Ward M, Donnelly DM, et al. $A$ randomised prospective comparison of percutaneous endoscopic gastrostomy and nasogastric tube feeding after acute dysphasic stroke. BMF 1996;312:13-6.

29 Wanklyn P, Cox N, Belfield P. Outcome in patients who require a gastrostomy after stroke. Age Ageing 1995;24:510-4. 